\title{
Active Commuting to School Among 36, 781 Spanish Children and Adolescents: A Temporal Trend Study
}

\author{
Patricia Gálvez-Fernández ( $\nabla$ pgalvez@ugr.es ) \\ University of Granada https://orcid.org/0000-0003-2871-9490 \\ Manuel Herrador-Colmenero \\ Universidad de Granada \\ Irene Esteban-Cornejo \\ University of Granada \\ José Castro-Piñero \\ Universidad de Cadiz \\ Javier Molina-García \\ Universitat de Valencia
}

Ana Queralt

Universitat de Valencia

Susana Aznar

Universidad de Castilla-La Mancha

Alberto Abarca-Sos

Universidad de Zaragoza

David González-Cutre

Universidad Miguel Hernandez de Elche

Josep Vidal-Conti

Universitat de les Illes Balears

Santiago Fernández-Muñoz

Universidad Carlos III de Madrid

Jerónimo Vida

Universidad de Granada

Alberto Ruiz-Ariza

Universidad de Jaen

Fernando Rodríguez-Rodríguez

Pontificia Universidad Catolica de Valparaiso

Diego Moliner-Urdiales

Universitat Jaume I

Emilio Villa-González 
Universidad de Granada

\section{Yahira Barranco-Ruíz}

Universidad de Granada

Francisco Javier Huertas-Delgado

Universidad de Granada

\section{Sandra Mandic}

University of Otago

\section{Palma Chillón}

Universidad de Granada

\section{Research}

Keywords: active transport, youth, cycling, walking, trends, school

Posted Date: July 23rd, 2020

DOI: https://doi.org/10.21203/rs.3.rs-46091/v1

License: (c) (i) This work is licensed under a Creative Commons Attribution 4.0 International License. Read Full License 


\section{Abstract \\ Background}

Active commuting to school (ACS) is an important source to increase the total daily physical activity in youth and improve their health. How the ACS rates change along the time is of interest. The objective of this study was to examine trends in the rates of ACS in a large sample of Spanish children and adolescents aged 6-18 years from 2010 to 2017. The study period included the economic crisis in Spain (2008 to 2013) and secondary analysis was conducted to compare ACS rates during and after the economic crisis.

\section{Methods}

To investigate trends in ACS among Spanish children and adolescents, data were obtained from 28 studies conducted across Spain. The study sample comprised 18,343 children (6 to 11.9 years old; $50.5 \%$ girls) and 18,438 adolescents (12 to 18 years old; $49.5 \%$ girls). The overall trends in ACS were evaluated using multilevel logistic regression analysis.

\section{Results}

The rates of ACS in Spanish children and adolescents did not change significantly during the 2010-2017 period, except a sporadic increase in the rate of ACS in adolescents in 2012-2013. No significant association between the ACS and the economic crisis time period in either children or adolescents were found. These findings are in contrast to recently reported declines in ACS rates in other countries.

\section{Conclusions}

Strong partnerships between researchers, public health practitioners, policy-makers and communities, as well as long-term commitment and evaluations of interventions aiming to increase ACS are necessary to ensure positive results in the long term.

\section{Background}

A growing body of evidence demonstrates that regular physical activity has multiple health benefits for children and adolescents (1). However, the majority of children and adolescents worldwide do not meet the current recommendations of engaging in at least 60 minutes of moderate-to-vigorous physical activity per day $(2,3)$. In Spain, around $80 \%$ of children and adolescents are not sufficiently physically active (2). 
Active commuting to school (ACS), defined as the use of active means of transport, such as walking and/or cycling to and from school, represents an opportunity to integrate physical activity into everyday life of children and adolescents (4). Importantly, ACS is associated with numerous health benefits for individuals and the society including higher physical activity levels $(5,6)$, reduced risk of development of metabolic diseases $(7)$, greater interpersonal relationships $(8,9)$ in children and adolescents, increased independent mobility in these age groups (10) as well as it provides environmental and economic benefits (11).

Despite numerous benefits, rates of ACS vary across countries $(12,13)$. A growing number of studies has also reported the decline in the prevalence of ACS among children and adolescents in the last decades in the United States $(14,15)$, the United Kingdom (16), Spain (17), Switzerland (18), Czech Republic (19), Vietnam $(20)$, Australia $(21,22)$ and New Zealand $(23,24)$. Among European children, a rate of decline in ACS ranged from 7\% decrease in Switzerland between 1994 and 2005 (18) to 9\% decrease in the United Kingdom between 1975 and 1994 (16). More pronounced declines in ACS rates have been reported among European adolescents ranging from 15\% in Spain between 2001 and 2007 (17) to 20\% in Czech Republic between 2006 and 2014 (19). However, more recent evidence is lacking. The previous study from Spain included only two measurement points (2001-2007) and was conducted 13 years ago (17). Given the global trends of decreasing levels of physical activity among children and adolescents (2) and rapid urbanisation in many countries, understanding the recent trends in ACS is essential to evaluate country-specific needs for future interventions. Decrease in physical activity of children and adolescents and rapid urbanisation have also been observed in Spain in recent decades (25). Therefore, this study analyzed the trends in the rates of ACS in a large sample of Spanish children and adolescents aged 618 years from 2010 to 2017. The study period also included the economic crisis in Spain (2008 to 2013) and secondary analysis was conducted to compare ACS rates during and after the economic crisis.

\section{Methods}

\section{Study design}

This study analyzed cross-sectional data on modes of commuting to and/or from school from 28 studies conducted across Spain. Data were obtained from original studies conducted by research centers and local/regional public institutions between 2010 and 2017 and included Spanish children and adolescents. This cross-sectional study is the first part of the PACO Study ("Cycle and Walk to School Study") that focuses on promoting ACS among Spanish children and adolescents.

\section{Procedure}

Firstly, the potential Spanish studies that collected mode of commuting to/from school data were searched using the following three approaches: 1) electronic search of studies conducted in Spain, 2) request through an oral presentation at the National Conference "Childhood and Mobility" organized by the Spanish Ministry of Agriculture, Food and Environment in November 2016, and 3) request through and oral presentation at the National Congress "The Bike and the City" in May 2017. After the initial 
search for relevant studies (June, 2017), two researchers (PC, FJHD) contacted by email 20 Spanish research centers and local/regional public institutions to invite them to participate in this study, providing information about the study and process for gathering relevant existing research data from individual studies. All 20 invited research centers and local/regional public institutions agreed to take part in the study. They were asked to provide the following data: the data collection date (month and year), school location, the participants' age, gender, mode of commuting to and/or from school, as well as other relevant data about study participants including socioeconomic status, if available. The inclusion criteria for selecting these studies were that: 1) data were collected using a questionnaire, 2) participant-level data were available, 3) studies provided data collected until the end of the recruitment period (i.e., 2017), and 4) study provided data on mode of commuting to and/or from school, age, gender, school location, and data collection date. A total of 34 studies met those inclusion criteria.

\section{Sample}

The current study included participant-level data collected between 2010 and 2017 (from the 34 studies that met those inclusion criteria, six studies were excluded because of data collected before 2010) from Spanish children and adolescents aged between 6 and 18 years who had data for gender, age, ACS and school location. In addition, researchers collected information about population density and income of the cities and towns where schools were located. Data from all the 28 studies were merged into a database with a final sample size of 48,373 children and adolescents. From this sample, a total of 11,592 (24\%) participants were excluded because lacking data on gender $(n=294)$, age $(n=299)$, mode of commuting to and/or from school $(n=4,638)$, and school location $(n=401)$, participants being under 6 years of age or over 18 years of age $(n=5,429)$ and in addition, those using a combination of active and passive modes on a single journey to/from school $(n=531)$. The process of merging individual-level data from multiple studies into a final dataset was checked by two researchers (PGF, FJHD). The final sample size included 36,781 children and adolescents from 294 Spanish localities; namely, 18,343 children from 6 to 11.9 years old; and 18,438 adolescents from 12 to 18 years old (Fig. 1). Description of the main characteristics and data collection dates of the 28 studies included in this analysis are presented in the additional file 1 (see supplementary information file 1).

\section{Mode of commuting to and from school}

In all studies, children and adolescents self-reported their mode(s) of commuting to and from school, using a range of survey questions across studies which are summarized in Fig. 2 . Four out of 28 studies (14.3\%) collected data on the frequency of commuting to/from school (i.e., 1 study collected data on the number of school days (from 0 to 5 ) using each mode of commuting to and from school separately; 1 study collected data on the number of weekly days (from 0 to 5 ) using ACS (such as walking, cycling or skating); and 2 studies collected data on the number of weekly travels (from 0 to 10) using each mode of commuting to and from school separately). Twenty-four studies (85.7\%) collected data on the usual mode of commuting to/from school (i.e., 12 studies asked about the usual mode of commuting to and from school separately and 12 studies asked about the usual mode of commuting to or from school). 
Based on their responses options on how they travelled to and/or from school, participants were categorized into either active or passive commuters (Fig. 2). Participants who reported walking, cycling, and/or using a non-motorized scooter to travel to/from school were categorized as active commuters. Participants who reported travelling to/from school by school bus, public bus, train/metro, taxi, moto, and/or by car were categorized as passive commuters. Participants using multiple modes as part of their school journey (i.e. using two or more different modes of commuting for the same trip) were included in this analysis only if both modes could be included in the same category (i.e., active or passive), as described above.

The frequency of commuting to/from school questions were re-categorized according to the number of active days or travels. Consequently, participants were categorized as "active" if reported (see Fig. 2): $\geq 2$ active travel days out of 5 school days (questions \#1 and \#2) and $\geq 4$ active travel trips out of 10 school trips per week (4) (question \#3). The usual mode of commuting to/from schoo/were categorized as active when participants reported $\geq 1$ active travel per day out of 2 daily school trips (26) (question \#4). Those who were not categorized as "active commuting", were categorized as "passive commuting" users.

Last, a dichotomous variable "active commuting" versus "passive commuting" was created for the statistical analysis: "active" (including children and adolescents who actively commuted to school, from school or to/from school) and "passive" (including children and adolescents who passively commute to school, from school or to/from school).

\section{Time period}

This study included data collected between 2010 and 2017. The time period was divided into 2-year periods: $2010-2011,2012-2013,2014-2015$, and $2016-2017$ according to other studies $(27,28)$ and to guarantee a similar sample size in each period providing four time periods to examine the trends. Additionally, the economic crisis in Spain was from 2008 to 2013. Therefore, data in this study were analyzed for the periods before the economic crisis (2010-2013) and after the crisis (2014-2017) (29).

\section{Sociodemographic characteristics}

Individual data included age and gender of the participants. The characteristics of the school location used in the current statistical analyses were population density and income. The population density (number of inhabitants per locality area in $\mathrm{km}^{2}$ ) was obtained from the Ministry of Finance and Public Administration of Spain, using the available data closest to the data collection year in each locality. The income of the data collection year was obtained from the Tax Agency Spanish Public (https://www.agenciatributaria.es/). The population density and income were categorized into a dichotomous variable (low/high) using the median.

\section{Statistical analysis}

Descriptive statistics were reported for the participants data (i.e., age, gender, ACS) and for the schools' locations data (i.e., population density and income), separately for each age group (i.e., children and adolescents) and each time period (i.e., 2-year periods). All analyses were conducted separately for 
children and adolescents due to previous evidence of different patterns of commuting to school in those two age groups $(30,31)$, greater home-to-school distances to high schools versus primary schools (32) and different barriers for ACS among children versus adolescents (33). Means and standard deviations were reported for continuous variables, and frequencies and percentages were reported for categorical variables. To analyze the P-trend of each variable by the time period, one-way ANOVA for continuous variables and chi squared for categorical variables were performed. The association between ACS and time period was assessed using multilevel logistic regressions, to take in account that participants come from heterogeneous schools' locations. In this analysis, participants (level 1) were nested in schools' locations (level 2). Age, gender, ACS, and time period were included at the level 1 whereas population density and income were included at the level 2 . After testing the goodness of fitness of the model, the multilevel model fitted better without population density and income variables from the level 2 . The multilevel logistic regression models were fitted and conducted separately for children and adolescents, where ACS was entered into the models as the dependent variable and the time period as independent variable. Age and gender were included as covariates. To analyze the potential relationship of age, gender and localities' income in the previous multilevel logistic regressions, the individual interaction effects between each of these variables with time period in relation to ACS were separately examined for children and adolescents.

Moreover, an additional analysis was performed to analyze the associations between ACS and the localities' income in the period studied (2010-2017) using logistic regression. Finally, two additional logistic regression analyses were performed to study the relationship between the time period, classified as before and after the economic crisis (i.e., 2010-2013 and 2014-2017, respectively), with the ACS and the localities' income, in separate models. Database management and the analyses were performed using STATA v.13 and statistical significance was set at $p<0.05$.

\section{Results}

Data from 18,343 children (6 to 11.9 years old; $50.5 \%$ girls) and 18,438 adolescents ( 12 to 18 years old; $49.5 \%$ girls) were analyzed. In both age groups, $60 \%$ of participants used ACS. Across four time periods, there were significant differences in participants' age, gender, rates of ACS and schools' locations data (i.e., population density and income) (all, $p<0.001$; Table 1). Rates of ACS across the four time periods ranged between $58-65 \%$ in children and between $55-66 \%$ in adolescents. 
Table 1 . Descriptive characteristics of the study participants by time period.

\begin{tabular}{|c|c|c|c|c|c|c|}
\hline & Total sample & $2010 / 2011$ & $2012 / 2013$ & $2014 / 2015$ & $2016 / 2017$ & $\begin{array}{c}\mathrm{p} \\
\text { (Trend) }\end{array}$ \\
\hline Children & $\mathrm{n}=18,343$ & $\mathrm{n}=4,007$ & $n=3,053$ & $\mathrm{n}=9,438$ & $\mathrm{n}=1,845$ & \\
\hline Age $(\bar{X} \pm$ SD $)$ & $8.93 \pm 1.68$ & $8.95 \pm 1.57$ & $9.15 \pm 1.86$ & $8.82 \pm 1.66$ & $9.06 \pm 1.72$ & $<0.001$ \\
\hline Female $[\mathrm{n}(\%)]$ & $9,255(50.5)$ & $2,044(51.1)$ & $1,559(51.1)$ & $4,729(50.1)$ & $923(50.0)$ & 0.672 \\
\hline \multicolumn{7}{|l|}{$\mathrm{ACS}$} \\
\hline All $[\mathrm{n}(\%)]$ & $11,062(60.3)$ & $2,488(62.1)$ & $1,926(65.6)$ & $5,186(58.7)$ & $1,075(58.2)$ & $<0.001$ \\
\hline Female $[\mathrm{n}(\%)]$ & $5,528(59.7)$ & $1,276(62.2)$ & $960(64.47)$ & $2,710(57.5)$ & $542(58.7)$ & $<0.001$ \\
\hline Male $[\mathrm{n}(\%)]$ & $5,534(60,9)$ & $1,276(61,8)$ & $1,000(66,5)$ & $2,796(59,4)$ & $532(57.7)$ & $<0.001$ \\
\hline Population density (median) & 682.859 & 16448.73 & 650.537 & 152.872 & 3093.23 & $<0.001$ \\
\hline Income (median) & 20,861 & 24,906 & 19,625 & 19,206 & 21,751 & $<0.001$ \\
\hline Adolescents & $\mathrm{n}=18,438$ & $\mathrm{n}=4,356$ & $\mathrm{n}=7,755$ & $\mathrm{n}=5,014$ & $\mathrm{n}=1,313$ & \\
\hline Age $(\bar{X} \pm$ SD $)$ & $14.11 \pm 1.58$ & $14.26 \pm 1.70$ & $14.38 \pm 1.41$ & $13.56 \pm 1.48$ & $14.32 \pm 1.93$ & $<0.001$ \\
\hline Female $[\mathrm{n}(\%)]$ & $8,782(49.1)$ & $2,099(48.2)$ & $3,787(48.8)$ & $2,469(49.4)$ & $702(53.3)$ & 0.008 \\
\hline \multicolumn{7}{|l|}{$\mathrm{ACS}$} \\
\hline All $[\mathrm{n}(\%)]$ & $11,104(60.2)$ & $2,603(60.1)$ & $4,776(61.9)$ & $2,526(55.6)$ & $855(66.2)$ & $<0.001$ \\
\hline Female $[\mathrm{n}(\%)]$ & $5,389(59,5)$ & $1,229(58.5)$ & $2,349(61.9)$ & $1,352(54.9)$ & $459(65.5)$ & $<0.001$ \\
\hline Male $[\mathrm{n}(\%)]$ & $5,715(60,9)$ & $1,391(61,3)$ & $2,462(62.0)$ & $1,452(57.1)$ & $410(67.1)$ & $<0.001$ \\
\hline Population density (median) & 917.565 & 16448.73 & 389.982 & 184.220 & 911.615 & $<0.001$ \\
\hline Income (median) & 20,861 & 24,906 & 16,625 & 20,512 & 21,005 & $<0.001$ \\
\hline
\end{tabular}

The results of the multilevel logistic regression between ACS and time period, controlled by age and by gender, and clustered by children and adolescents, are shown in the Fig. 3. In children, there was no association between ACS and the time period. In adolescents, there was one significant association, and they were more likely to commute actively in 2012-2013 than in 2016-2017 (OR: 1.30, 95\% Cl: 1.06$1.58, p \leq 0.01)$. There were no interactions between age, gender, and localities' income with the time period (all $p>0.1$; data not shown).

Regarding the associations between ACS and localities' income during the study period (2010-2017), children attending schools in localities with low income had lower odds of use ACS than their counterparts attending schools in localities with high income (odds ratio $(95 \% \mathrm{Cl}): 0.80(0.75-0.86), \mathrm{p}<$ 0.001). In adolescents, those attending schools in low income localities had higher odds of ACS compared to those attending schools in high income localities (1.22 (1.15-1.31), $p<0.001)$ (Table 2). 
Table 2

Associations between ACS and localities' income for children and adolescents in the period studied (2010-2017) adjusting by age and gender.

\begin{tabular}{|c|c|c|c|c|c|c|c|}
\hline \multirow[t]{2}{*}{ ACS } & \multicolumn{3}{|c|}{ Children $(n=18,005)$} & & \multicolumn{3}{|c|}{ Adolescents $(n=18,392)$} \\
\hline & OR & $95 \% \mathrm{Cl}$ & $\mathrm{p}$ value & & OR & OR & OR \\
\hline High & 1 & Reference & & High & 1 & Reference & \\
\hline Low & 0.80 & $0.75-0.86$ & 0.001 & Low & 1.22 & $1.15-1.31$ & 0.001 \\
\hline \multicolumn{8}{|c|}{ OR = Odd Ratio } \\
\hline \multicolumn{8}{|c|}{$\mathrm{IC}=$ Confidence Interval } \\
\hline
\end{tabular}

No significant association between the ACS and the economic crisis time period in either children or adolescents were found. Using the post-economic crisis period (2014-2017) as a reference, the odds of ACS were not significantly different during the economic crisis period (2010-2013) in either children (1.06 (0.99-1.14), $p=0.080)$ or adolescents (1.04 (0.97-1.12), $p=0.252)$ (Table 3$)$.

Table 3

Associations between ACS and crisis time period (2010-2013) and after economic crisis time period (2014-2017) for children and adolescents adjusting by age and gender.

\begin{tabular}{|c|c|c|c|c|c|c|c|}
\hline \multirow[t]{2}{*}{ ACS } & \multicolumn{3}{|c|}{ Children $(n=18,343)$} & & \multicolumn{3}{|c|}{ Adolescents $(n=18,438)$} \\
\hline & OR & $95 \% \mathrm{Cl}$ & $\mathrm{p}$ value & & OR & $95 \% \mathrm{Cl}$ & $p$ value \\
\hline 2014-2017 & 1 & Reference & & $2014-2017$ & 1 & Reference & \\
\hline $2010-2013$ & 1.06 & $0.99-1.14$ & 0.080 & $2010-2013$ & 1.04 & $0.97-1.12$ & 0.252 \\
\hline \multicolumn{8}{|c|}{ OR = Odd Ratio } \\
\hline
\end{tabular}

Significant association between the localities' income and the economic crisis time period in either children or adolescents were found (all, $p<0.001$ ) (data not shown, see additional file 1 , supplementary information file 2).

\section{Discussion}

This study analyzed the trends of ACS between 2010 and 2017 in a large sample of Spanish children and adolescents, using cross-sectional data from 28 studies. The rates of ACS in Spanish children and adolescents did not change significantly during the 2010-2017 period, except a sporadic increase in the rate of ACS in adolescents in 2012-2013.

Globally, the prevalence of ACS varies across countries ranging from $11-53 \%$ in children $(19,34-36)$ and from $28-70 \%$ in adolescents $(13,34-37)$. In the present study, $60 \%$ Spanish children and adolescents 
were using ACS during the 2010-2017 period. The findings in the current study showed higher rates of ACS compared to those reported in most other countries. Available evidence suggests a wide range of individual, social, environmental, and policy factors influence ACS in children and adolescents (38), with distance to school being one of the major determinants of ACS (39). In addition, factors such as the heterogeneity of research questions and methods of assessing the mode of commuting to school differ between countries (40). These differences may contribute to cross-country variations in prevalence of ACS among children and adolescents observed in this and other studies $(13,19,34-36)$. Therefore, interventions aiming to increase higher rates of ACS are necessary from a public health perspective to achieve increasing physical activity and reducing time spent in sedentary behaviors among Spanish children and adolescents.

In the present study, there were no significant trends for changes in ACS rates among Spanish children and adolescents during the 2010-2017 period. Although several studies reported decline in ACS rates among children and adolescents prior to 2010 (14-18, 20-23), only two studies reported ACS rate changes in children and adolescents after $2010(19,24)$. Specifically, a study from Czech Republic that collected data up to 2014 reported a general decreasing trend of 20\% between 2006 and 2014 (19). A recent research from New Zealand which analyzed ACS rates during the 2014-2018 period based on national surveys (24) reported a trend of declining ACS rates. This general decreasing trend observed in the previous studies in children and adolescents is in contrast to the results of this study, where the rates of ACS in Spanish children and adolescents have not changed significantly during the 2010-2017 period, with an exception of a significant increase in ACS rates in adolescents in the years 2012/2013 compared to $2016 / 2017$. No significant change in ACS rates among Spanish children and adolescents during the 2010-2017 period is a promising result given the declines in ACS rate reported in other countries during the similar time period $(19,24)$. No decline in ACS rates in Spain during the 2010-2017 may reflect the changes that Spanish society had adopted into potentially more healthy and sustainable behaviors on a population level (http://www.estilosdevidasaludable.mscbs.gob.es), attenuating the previously reported and conclusive descent trend (14-18, 20-23). Several educational and socioeconomical reasons that may explain the present findings are discussed below.

No significant changes in ACS rates in children and adolescents might be a result of an educational process based on the recent concern related to healthy and environmental issues in our society (41). As a result, it is possible that Spanish families are adopting more healthy and sustainable behaviors, such as physically active lifestyle and reduced reliance on car transport (42). In fact, the Government of Spain has been aiming to promote health in children and adolescents in the recent years, with strategies such as the Nutrition, Physical Activity and Obesity Prevention (http://www.aecosan.msssi.gob.es). The increasing number of strategies targeted to promote ACS carried out in Spain in the recent years seems to have had a positive influence $(43,44)$. For example, the national educational law $(45)$ launched in 2013 , included as a novel content to promote ACS within educational curriculum, which facilitates promoting healthy behaviors in educational centers. Another example is the STARS Project (http://www.starsespaña.com), launched by the Spanish Directorate General of Traffic and local governments in 2016, that aims to empower and reward schools to promote sustainable and safe commuting among their students, 
including both walking and cycling. The program still continues nowadays in some schools across Spain (121 (1.5\%) primary and 73 (2.0\%) secondary public schools). Moreover, the Traffic Snake Game (https://www.trafficsnakegame.eu) originated in Belgium and Spain in 2014 has involved 226 (6\%) Spanish primary schools to date. This game encourages children, their parents and teachers to use forms of sustainable mobility when traveling to school including walking, cycling, using public transport or sharing the car among several. Therefore, these interventions may have contributed to stabilising the proportion of children and adolescents who use ACS in the 2010-2017 period in Spain.

A part of the time period of the present study included a financial crisis in Spain between 2008-2013 (29). Despite existence of a national survey about mode of commuting to work in adults between 2001 to 2011 , there is no previous national data about the changes of ACS during the financial crisis in Spain. Cross-sectional data collected in 2011 showed that Spanish youth whose parents did not work had higher levels of ACS than their peers whose parents were employed (46). When the associations between ACS and localities' income were analyzed for the 2010-2017 period, children attending schools in localities with low income were less likely to use ACS than whose with high income. Contrasting findings were observed in adolescents with those from low income localities being more likely to commute actively than whose from high income localities. In the present study, when ACS rates were compared between the financial crisis time (2010-2013) and after-crisis time (2014-2017), no significant differences in the odds of ACS were observed between the two periods in either children or adolescents. Even so, the odds ratio of reporting ACS were higher for the crisis time period than for the after-crisis time period although not significantly and borderline significantly in children. These results might show a lower use of private transportation compared to after-crisis, due to both the financial crisis time affecting most of the Spanish families or other personal decisions (47). These results must be interpreted with caution since the present study was not based on nationally representative samples of children and adolescents. However, using the current data in this study, we verified that in the crisis time period there was a lower income in the localities participants compared to the after crisis time period. Consequently, this financial crisis in Spain during the 2008-2013 period may have contributed to the stable trend observed in the ACS patterns compared to the previous reported decreased trends of ACS from previous studies $(15,18,19)$.

Moving forward, it would be helpful to monitor country-level ACS trends prospectively using data from nationally representative samples of children and adolescents (24) and the global monitoring of the country-level ACS which is already in progress as part of the Global Matrix project $(12,30)$. In fact, encouraging active commuting in general (including ACS) is aligned with the global policies aimed at promoting physical activity, such as, the World Health Organization's Global Action Plan on Physical Activity (GAPPA) 2018-2030 (48) and the Sustainable Development Goals (SDG) launched by United Nations (49). There needs to be a set of guidelines within and across countries on how the different methodological approaches and available data sources for monitoring and promoting ACS are handled (24). A specific key recommendation for future research might be to use a unique valid and reliable questionnaire for ACS data collection (50). Use of standardized questionnaire might help researchers to assess this ACS behavior with a valid measurement, allowing appropriate comparisons between studies. 
The main strengths of this study are a large sample size with participants from different locations within a country, a systematic and rigorous process for merging data from different studies, a novel and useful approach to combine response from a variety of survey questions used to assess the ACS across different studies (40) (see Fig. 2 for details). The outlined process for merging ACS data from multiple studies may help researchers, health promoters, transport planners and policy makers in their efforts to combine data related to mode of commuting to/from school from multiple sources of data. We previously reported the high heterogeneity in self-report questionnaires in studies assessing the mode of commuting to/from school conducted to date (40). This article provides a potential solution to standardize these diverse measurements.

The main limitations of this study are the use of data from nationally non-representative sample and lack home-to-school distance data. Other limitations include a diversity of questions used to self-report modes of commuting to school, the lack of individual level socioeconomic status, differences in sample size, sociodemographic characteristics of study participants as well as population density and income of school locations where data were collected each year. Further action-oriented research is needed to understand how social and infrastructure changes fit together to achieve healthy, equitable and sustainable transport and urban planning in modern cities and towns.

\section{Conclusions}

In the period 2010-2017, the rates of ACS in Spanish children and adolescents have remained stable. These findings are in contrast to recently reported declines in ACS rates in other countries. This might reflect the changes that Spanish society is acquiring into more healthy and sustainable behaviors maybe due to educational and socioeconomical changes. Strong partnerships between researchers, public health practitioners, policy-makers and communities as well as long-term commitment and evaluations of interventions aiming to increase ACS are necessary to ensure positive results in the long term.

\section{List Of Abbreviations}

ACS, active commuting to and from school

GAPPA, Global Action Plan on Physical Activity

SDG, Sustainable Development Goals

\section{Declarations}

\section{Acknowledgements}

The team would like to acknowledge the support of the following Spanish research centers and local/regional public institutions in providing data used in this study: Auguria (Ana Montalbán), Agenda 21 (Jerónimo Vida), Up \& Down (Irene Esteban, Pepe Castro), University of Valencia (Javier Molina y Ana 
Queralt), Autonomous University of Barcelona (Pau Avellaneda), University of Jaén (Alberto Ruiz), University of Zaragoza (Alberto Abarca), University of the Balearic Islands (Josep Vidal), La Biciclante (Luis González), La Ciclería, University of Santiago de Compostela (Rosaura Leis), University of Elche (David González), City Council of Zaragoza, Ma Asunción Recasens, Oscar Veiga, University of Castilla la Mancha (Susana Aznar), University Jaume I (Diego Moliner), University Carlos III (Santiago Fernandez), University of Granada (Palma Chillón, Emilio Villa, Carlos Rodríguez), University Católica de Valparaíso (Fernando Rodríguez) and University of Otago (Sandra Mandic).

\section{Funding}

The PACO Study was supported by the Spanish Ministry of Economy, Industry and Competitiveness and the European Regional Development Fund (DEP2016-75598-R, MINECO/FEDER, UE), and Spanish Ministry of Education and Vocational Training (FPU17/03934).Additionally, this study has been partially funded by the University of Granada, Plan Propio de Investigación 2016, Excellence actions: Units of Excellence; Unit of Excellence on Exercise and Health (UCEES), and by the Junta de Andalucía, Consejería de Conocimiento, Investigación y Universidades, European Regional Development Fund (ERDF), ref. SOMM17/6107/UGR. IE-C is supported by the Spanish Ministry of Economy and Competitiveness (RTI2018-095284-J-I00). The DADOS Study is funded by the Spanish Ministry of Economy and Competitiveness, MINECO (DEP2013-45515-R) and by the Jaume I University of Castellon, UJI (P1-1A2015-05).This study is part of a PhD thesis conducted in the Official Doctoral Program in Biomedicineof the University of Granada, Spain.

\section{Availability of data and materials}

The dataset supporting the conclusions of this article is available upon reasonable request to the corresponding author.

\section{Authors' contributions}

PG, PC and FJHD planned the study. All authors provided samples from children and adolescents with ACS data. PG and FJHD created a database with all studies. PG and MHC performed the statistical analyses and all authors participated in interpretation of the results and writing of the manuscript.

\section{Ethics approval and consent to participate}

The Medical Ethics Committee of University of Granada approved the PACO Study design, study protocols and informed consent procedure (case no. 162/CEIH/2016).

\section{Consent for publication}

Not applicable.

\section{Competing interests}


Authors have no competing interests to declare.

\section{References}

1. Poitras VJ, Gray CE, Borghese MM, Carson V, Chaput JP, Janssen I, et al. Systematic review of the relationships between objectively measured physical activity and health indicators in school-aged children and youth. Appl Physiol Nutr Metab. 2016;41(6 Suppl 3):197-239.

2. Guthold R, Stevens GA, Riley LM, Bull FC. Global trends in insufficient physical activity among adolescents: a pooled analysis of 298 population-based surveys with 1.6 million participants. Lancet Child Adolesc Health. 2020;4(1):23-35.

3. Physical Activity Guidelines Advisory Committee. (2008). Physical activity guidelines advisory committee report, 2008. Washington, DC: US Department of Health and Human Services, 2008, A1H14.

4. Chillón P, Hales D, Vaughn A, Gizlice Z, Ni A, Ward DS. A cross-sectional study of demographic, environmental and parental barriers to active school travel among children in the United States. Int J Behav Nutr Phys Act. 2014;11(1):61.

5. Peralta M, Henriques-Neto D, Bordado J, Loureiro N, Diz S, Marques A. Active Commuting to School and Physical Activity Levels among 11 to 16 Year-Old Adolescents from 63 Low- and Middle-Income Countries. Int J Environ Res Public Health. 2020;17(4).

6. Larouche R, Saunders TJ, Faulkner G, Colley R, Tremblay M. Associations between active school transport and physical activity, body composition, and cardiovascular fitness: a systematic review of 68 studies. J Phys Act Health. 2014;11(1):206-27.

7. Walker DJ, Maclntosh A, Kozyrskyj A, Becker A, McGavock J. The associations between cardiovascular risk factors, physical activity, and arterial stiffness in youth. J Phys Act Health. 2013;10(2):198-204.

8. Waygood EOD, Friman M, Olsson LE, Taniguchi A. Transport and child well-being: An integrative review. Travel behaviour society. 2017;9:32-49.

9. Wang X, Conway TL, Cain KL, Frank LD, Saelens BE, Geremia C, et al. Interactions of psychosocial factors with built environments in explaining adolescents' active transportation. Prev Med. 2017;100:76-83.

10. Wen LM, Merom D, Rissel C, Simpson JM. Weight status, modes of travel to school and screen time: a cross-sectional survey of children aged $10-13$ years in Sydney. Health Promot J Austr. 2010;21(1):57-63.

11. Gössling S, Choi A, Dekker K, Metzler D. The social cost of automobility, cycling and walking in the European Union. Ecol Econ. 2019;158:65-74.

12. Aubert S, Barnes JD, Abdeta C, Abi Nader P, Adeniyi AF, Aguilar-Farias N, et al. Global Matrix 3.0 Physical Activity Report Card Grades for Children and Youth: Results and Analysis From 49 Countries. J Phys Act Health. 2018;15(S2):251-73. 
13. Uddin R, Mandic S, Khan A. Active commuting to and from school among 106,605 adolescents in 27 Asia-Pacific countries. J Transp Health. 2019;15:100637.

14. Colley M, Buliung RN. Gender differences in school and work commuting mode through the life cycle: Exploring trends in the greater Toronto and Hamilton area, 1986 to 2011. Transp Res Rec. 2016;2598(1):102-9.

15. McDonald NC. Active transportation to school: trends among U.S. schoolchildren, 1969-2001. Am J Prev Med. 2007;32(6):509-16.

16. Black C, Collins A, Snell M. Encouraging walking: the case of journey-to-school trips in compact urban areas. Urban studies. 2001;38(7):1121-41.

17. Chillón P, Martínez-Gómez D, Ortega FB, Pérez-López IJ, Díaz LE, Veses AM, et al. Six-year trend in active commuting to school in Spanish adolescents. Int J Behav Med. 2013;20(4):529-37.

18. Grize L, Bringolf-Isler B, Martin E, Braun-Fahrländer C. Trend in active transportation to school among Swiss school children and its associated factors: three cross-sectional surveys 1994, 2000 and 2005. Int J Behav Nutr Phys Act. 2010;7(1):1-8.

19. Pavelka J, Sigmundová D, Hamřík Z, Kalman M, Sigmund E, Mathisen F. Trends in Active Commuting to School among Czech Schoolchildren from 2006 to 2014. Cent Eur J Publ Heal. 2017;25(Suppl 1):21-5.

20. Trang NH, Hong TK, Dibley MJ. Active commuting to school among adolescents in Ho Chi Minh City, Vietnam: change and predictors in a longitudinal study, 2004 to 2009. Am J Prev Med. 2012;42(2):120-8.

21. Meron D, Rissel C, Reinten-Reynolds T, Hardy LL. Changes in active travel of school children from 2004 to 2010 in New South Wales, Australia. Prev Med. 2011;53(6):408-10.

22. Van der Ploeg HP, Merom D, Corpuz G, Bauman AE. Trends in Australian children traveling to school 1971-2003: burning petrol or carbohydrates? Prev Med. 2008;46(1):60-2.

23. Hinckson EA, Garrett N, Duncan S. Active commuting to school in New Zealand children (20042008): a quantitative analysis. Prev Med. 2011;52(5):332-6.

24. Smith M, Ikeda E, Duncan S, Maddison R, Hinckson E, Meredith-Jones K, et al. Trends and measurement issues for active transportation in New Zealand's physical activity report cards for children and youth. J Transp Health. 2019;15:100789.

25. Grao-Cruces A, Sánchez-Oliva D, Segura-Jiménez V, Cabanas-Sánchez V, Martínez-Gómez D, Rodríguez-Rodríguez F, et al. Changes in compliance with school-based physical activity recommendations in Spanish youth: The UP\&DOWN longitudinal study. Scand J Med Sci Sports. 2019;29(4):554-65.

26. Chillón P, Ortega FB, Ruiz JR, Pérez IJ, Martín-Matillas M, Valtueña J, et al. Socio-economic factors and active commuting to school in urban Spanish adolescents: the AVENA study. Eur J Public Health. 2009;19(5):470-6.

27. Werneck GL, Costa CH, Walker AM, David JR, Wand M, Maguire JH. Multilevel modelling of the incidence of visceral leishmaniasis in Teresina, Brazil. Epidemiol Infect. 2007;135(2):195-201. 
28. Hodge A, Firth S, Jimenez-Soto E, Trisnantoro L. Linkages between decentralisation and inequalities in neonatal health: Evidence from Indonesia. The J Dev Stud. 2015;51(12):1634-52.

29. Domínguez-Mujica J, Díaz-Hernández R, PArrEño-cAstELLAno J. Migrating abroad to get ahead: the emigration of young Spanish adults during the financial crisis (2008-2013). Global change: Springer; 2016. pp. 203-23.

30. Tremblay MS, Barnes JD, González SA, Katzmarzyk PT, Onywera VO, Reilly JJ, et al. Global Matrix 2.0: Report Card Grades on the Physical Activity of Children and Youth Comparing 38 Countries. J Phys Act Health. 2016;13(11 Suppl 2):343-66.

31. Rodríguez-López C, Salas-Fariña ZM, Villa-González E, Borges-Cosic M, Herrador-Colmenero M, Medina-Casaubón J, et al. The threshold distance associated with walking from home to school. Health Educ Behav. 2017;44(6):857-66.

32. Chillón P, Panter J, Corder K, Jones AP, Van Sluijs EM. A longitudinal study of the distance that young people walk to school. Health Place. 2015;31:133-7.

33. Huertas-Delgado FJ, Herrador-Colmenero M, Villa-González E, Aranda-Balboa MJ, Cáceres MV, Mandic S, et al. Parental perceptions of barriers to active commuting to school in Spanish children and adolescents. Eur J Public Health. 2017;27(3):416-21.

34. Kontou E, McDonald NC, Brookshire K, Pullen-Seufert NC, LaJeunesse S. U.S. active school travel in 2017: Prevalence and correlates. Prev Med Rep. 2020;17:101024.

35. Australia AHK. Muscular fitness: It's time for a jump start! 2018 report card on physical activity for children and young people. 2018.

36. Smith M, Ikeda E, Hinckson E, Duncan S, Maddison R, Meredith-Jones K, et al. Results from New Zealand's 2018 Report Card on Physical Activity for Children and Youth. J Phys Act Health. 2018;15(S2):390-2.

37. Tyler R, Mannello M, Mattingley R, Roberts C, Sage R, Taylor SR, et al. Results From Wales' 2016 Report Card on Physical Activity for Children and Youth: Is Wales Turning the Tide on Children's Inactivity? J Phys Act Health. 2016;13(11 Suppl 2):330-6.

38. Panter JR, Jones AP, Van Sluijs EM. Environmental determinants of active travel in youth: a review and framework for future research. Int J Behav Nutr Phys Act. 2008;5(1):34.

39. Ikeda E, Stewart T, Garrett N, Egli V, Mandic S, Hosking J, et al. Built environment associates of active school travel in New Zealand children and youth: A systematic meta-analysis using individual participant data. J Transp Health. 2018;9:117-31.

40. Herrador-Colmenero M, Pérez-García M, Ruiz JR, Chillón P. Assessing modes and frequency of commuting to school in youngsters: a systematic review. Pediatr Exerc Sci. 2014;26(3):291-341.

41. Menor Rodríguez MJ, Aguilar Cordero MJ, Mur Villar N, Santana Mur C. Efectividad de las intervenciones educativas para la atención de la salud. Revisión sistemática MediSur. 2017;15(1):71-84.

42. Pérez K, Olabarria M, Rojas-Rueda D, Santamariña-Rubio E, Borrell C, Nieuwenhuijsen M. The health and economic benefits of active transport policies in Barcelona. J Transp Health. 2017;4:316-24. 
43. Ariza C, Martínez FS, Martínez OJ, Serral G, Bálic MG. La actividad física en la promoción de la salud en la escuela. Tándem: Didáctica de la educación física. 2016(52):27-33.

44. Pascual VC, Sánchez AM, Toledano FL, del Moral AM, de Victoria Muñoz EM, Martínez GP, et al. Informe del Comité Científico de la Agencia Española de Consumo, Seguridad Alimentaria y Nutrición (AECOSAN) sobre objetivos y re-comendaciones nutricionales y de actividad física frente a la obesidad en el marco de la Estrategia NAOS. Revista del Comité Científico de la AESAN. 2014;19:95209.

45. Organic Law 8/2013 of December 9th, for the Improvement of Educational Quality.

46. Rodríguez-López C, Villa-González E, Pérez-López IJ, Delgado-Fernández M, Ruiz JR, Chillón P. Family factors influence active commuting to school in Spanish children. Nutr Hosp. 2013;28(3):756-63.

47. Romero-Jordán D, Sanz-Sanz JF, Castañer-Carrasco JM. Sobre la regresividad de la imposición indirecta en España en tiempos de crisis: un análisis con microdatos de hogares. Papel de Econ Esp. 2013;135:172-83.

48. Organization WH. Global action plan on physical activity 2018-2030: more active people for a healthier world: World Health Organization; 2019.

49. Nations U. Transforming our world: The 2030 agenda for sustainable development. General Assembley 70 session. 2015.

50. Chillón P, Herrador-Colmenero M, Migueles JH, Cabanas-Sánchez V, Fernández-Santos JR, Veiga ÓL, et al. Convergent validation of a questionnaire to assess the mode and frequency of commuting to and from school. Scand J Public Health. 2017;45(6):612-20.

\section{Figures}




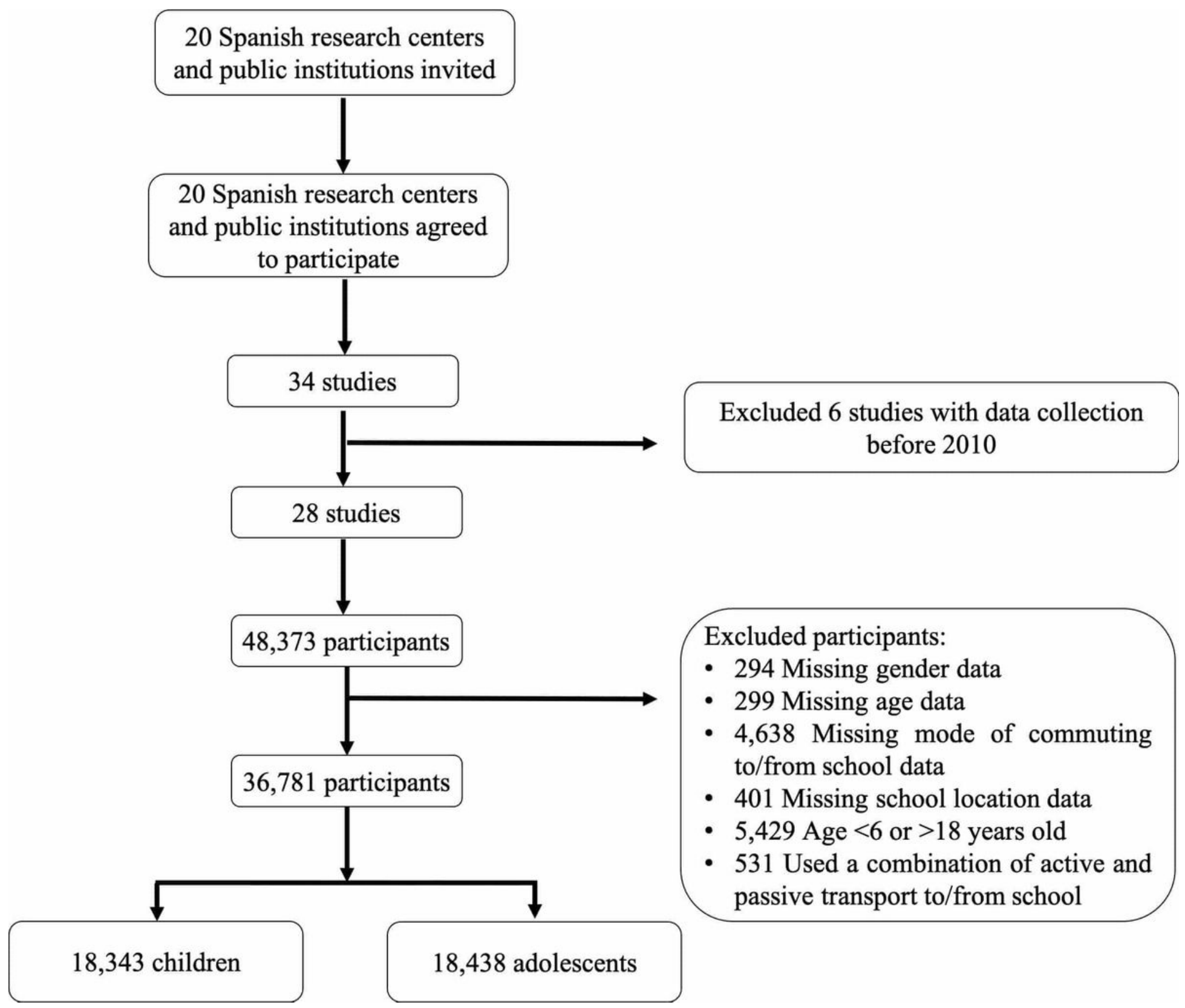

Figure 1

Flowchart of the study participants. 


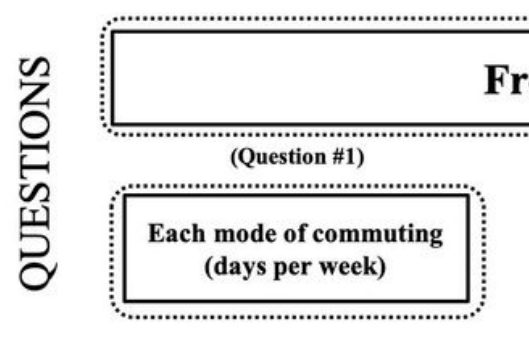

Frequency of commuting

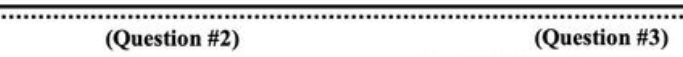

(Question \#2)

(Question \#3)

Active mode of commuting (days per week)

Each mode of commuting (travels per week)
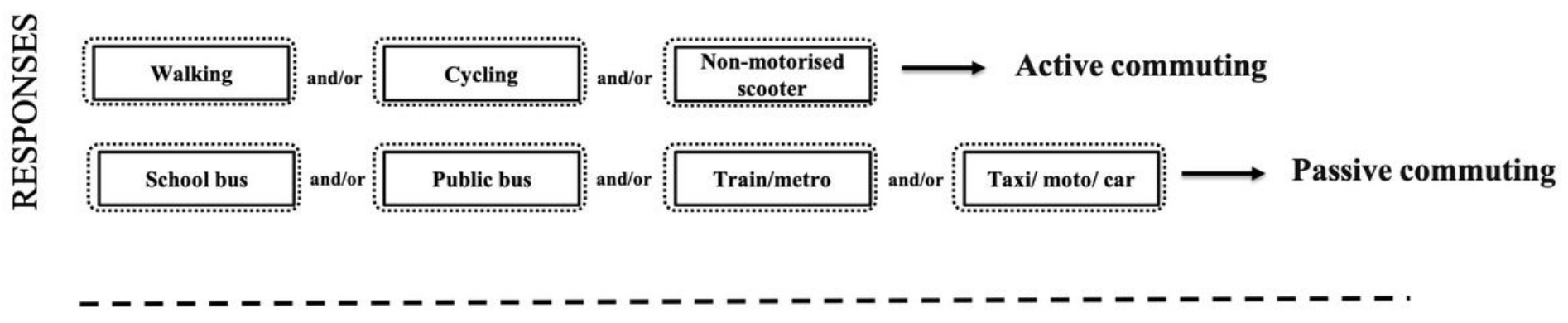

Z
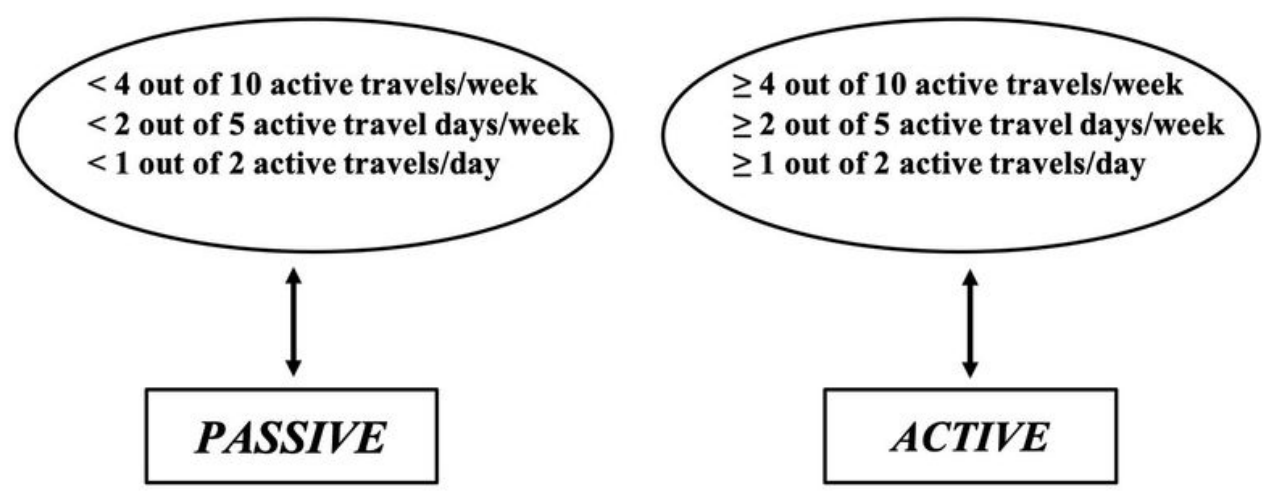

Figure 2

Categorization of the self-reported questions of modes of commuting to/from school, into active and passive commuting modes. 


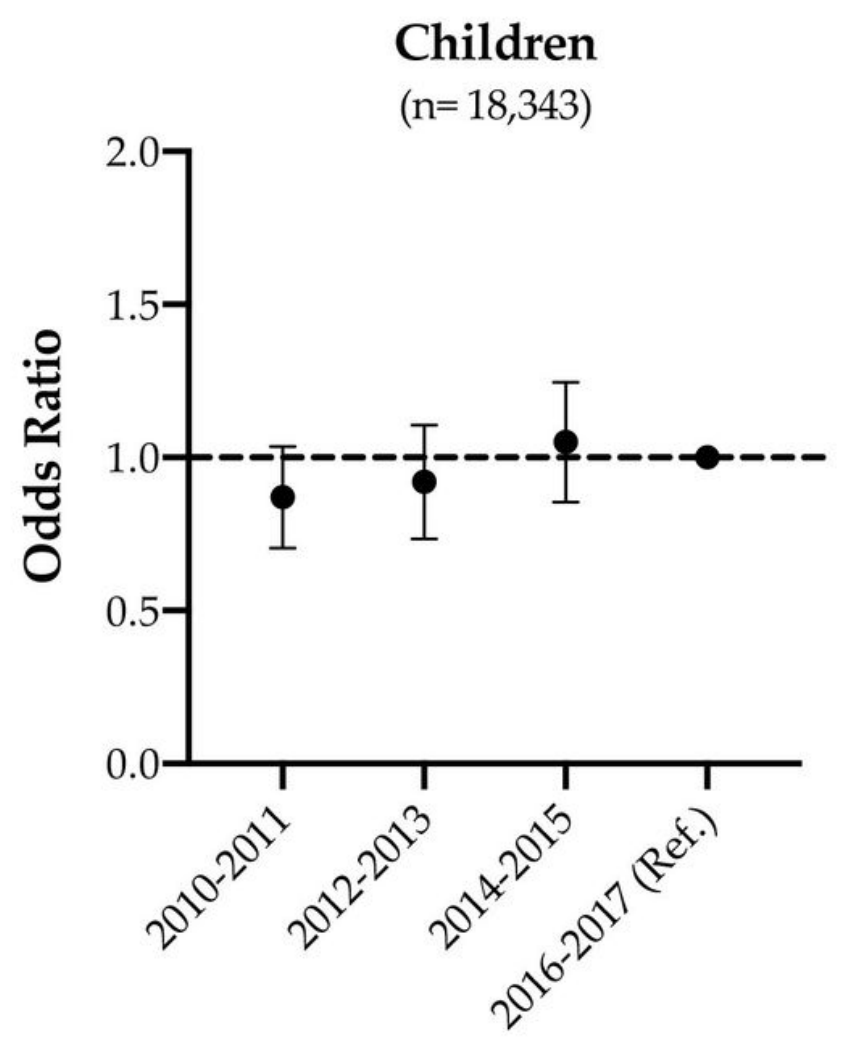

Survey years

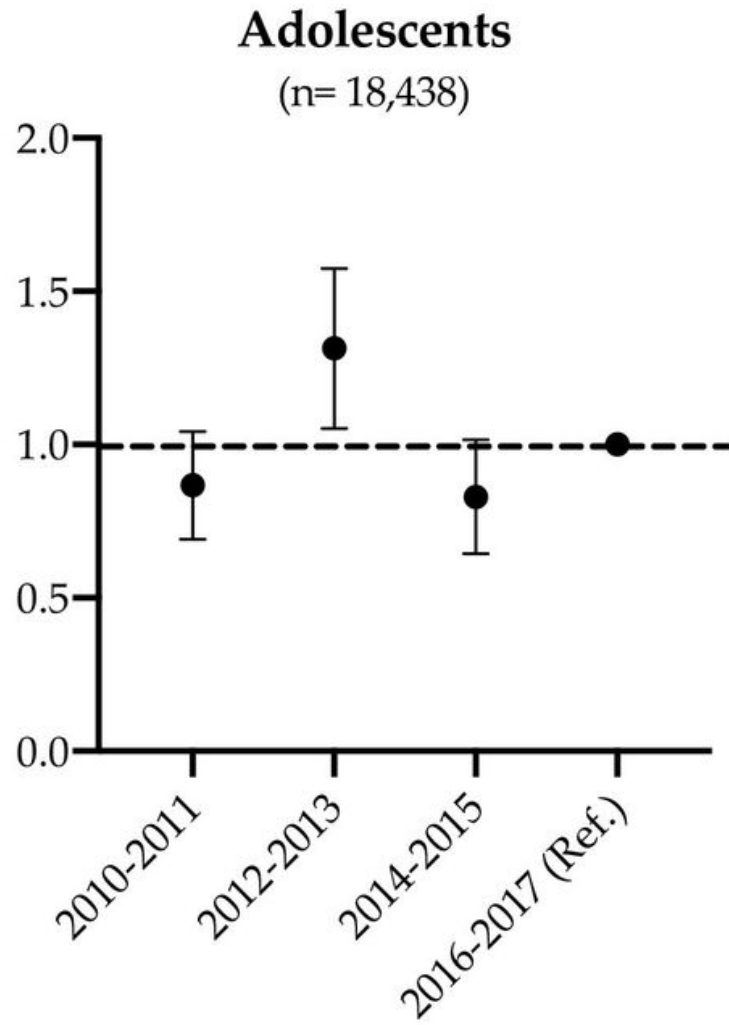

Survey years

\section{Figure 3}

Associations between ACS and time period for children and adolescents adjusted by age and gender. Notes. All odds ratios were not significant, except the period 2012-2013 in adolescents $(p=0.009)$.

\section{Supplementary Files}

This is a list of supplementary files associated with this preprint. Click to download.

- Supplementaryinformation.pdf 